\title{
Contribuição da Fisioterapia para o bem-estar e a participação De dois alunos com Distrofia Muscular de Duchenne no ensino
} REG ULAR

\author{
ThE CONTRIBUtion OF PhySIOTheRAPy FOR THE WELl-being AND

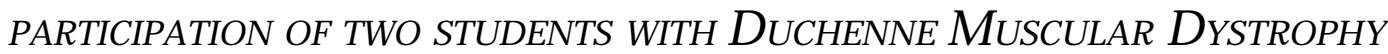

IN REGULAR SCHOOL

\author{
Flávia de Freitas PENA ${ }^{1}$ \\ Fernanda Cid ROSOLÉM² \\ Ângela Maria Sirena ALPINO ${ }^{3}$
}

\begin{abstract}
RESUM O: a Distrofia Muscular de Duchenne (DMD) é a mais grave e incapacitante dentre as miopatias infantis. As crianças enfraquecem progressivamente, sendo comum o óbito por infecção respiratória no final da adolescência. Os primeiros sintomas são percebidos na idade pré-escolar por professores ou cuidadores. Este estudo teve por objetivo verificar os efeitos de uma proposta de consultoria colaborativa da fisioterapia junto às professoras de sala e de Educação Física de dois alunos com DMD, estendendo-se a visita ao ambiente domiciliar de um deles, que apresentava grave comprometimento funcional, no sentido de melhorar sua participação e conforto na escola e em casa, contextos significativos no convívio diário. Foram feitas visitas à escol a dos dois al unos e à residência de um deles para investigação de suas necessidades reais. Os dados foram coletados por meio de entrevistas com os alunos participantes, com suas professoras de sala e de Educação Física e com os pais daquele gravemente comprometido. As ações abrangeram adaptação da mobília escolar, materiais e recursos de baixa tecnologia para uso dos alunos com DMD e orientações especializadas às professoras participantes e aos pais do aluno mais comprometido. Constatouse que a abordagem fisioterápica ecológica, orientada a adaptações ambientais e planejamento colaborativo de atividades, proporcionou algum apoio e conforto aos alunos participantes e favoreceu seu envolvimento/ participação na escola, além de contribuir para a capacitação específica de suas professoras. Todavia, as adaptações na residência e a orientação aos pais revelaram-se medidas essenciais para proporcionar algum conforto e autonomia ao aluno gravemente comprometido, no ambiente domiciliar.
\end{abstract}

PALAVRAS-CHAVE: Distrofia Muscular de Duchenne; consultoria colaborativa; fisioterapia; educação especial.

A BST RACT: Duchenne Muscular Dystrophy (DMD) is among the most serious and incapacitating childhood myopathies. Children progressively lose strength and usually die from respiratory infection by the end of their adolescence. The first symptoms are usually noticed in early childhood by teachers or caregivers. This study aimed to analyze the effects of collaborative consultation and planning proposal involving physiotherapy with classroom teachers and physical education teachers of two students with DMD, who presented severely limiting functional abilities; the objective was to improve their participation and comfort in the two most significant contexts of their daily lives: at school and at home. Visits to the two students'

\footnotetext{
${ }^{1}$ Fisioterapeuta residente de Fisioterapia em Pediatria do Hospital Universitário da Universidade Estadual de Londrina - HU/ UEL - iaiapena@yahoo.com.br; flavia_f_pena@yahoo.com.br

${ }^{2}$ Fisioterapeuta graduada pela Universidade Estadual de Londrina/ UEL. fercid@sercomtel.com.br

${ }^{3}$ Fisioterapeuta. Doutora em Educação Especial - Área de concentração: Educação do Indivíduo Especial. Docente do Departamento de Fisioterapia da Universidade Estadual de Londrina/ UEL. angelasiral@uel.br
} 
schools and to one of their homes were undertaken, in order to investigate their actual needs. Data was collected through interviews with the students, their parents, classroom teachers and physical education teachers. The strategies that were developed involved the adaptation of school furniture, acquisition of low tech materials and resources for the students' use and promotion of specialized orientations for the teachers involved and parents of the student with greater physical needs. It was possible to observe that the ecologic physiotherapy approach, aimed at environmental adaptations and collaborative planning of activities, provided some help and comfort for the participating students and enabled greater involvement/ participation at school, besides contributing to the teachers' development. Furthermore, the adaptations of the students' homes and supervision of the parents were demonstrated to be essential measures as they provided some comfort and autonomy to the student with more severe limitations in the home environment.

KEYWORDS: Duchenne Muscular Dystrophy; collaborative consultation; physiotherapy; special education.

\section{INTROdUÇão}

A International Classification of Impairment Disability and $\mathrm{H}$ andicap ICIDH (WHO, 1980), traduzida em português como Classificação Internacional de Deficiência, Incapacidade e Impedimento, define $D$ eficiência como perda ou anormalidade de estrutura ou função psicológica, fisiológica ou anatômica que representa a exteriorização de um estado patológico e reflete um distúrbio orgânico. Incapacidade traduz a restrição da habilidade para desempenhar atividades e ter comportamentos essenciais à vida diária e D esvantagem expressa o prejuízo para o indivíduo, resultante de deficiência ou incapacidade, que limita ou impede o desempenho de papéis sociais/ culturais e reflete sua adaptação ao meio ambiente.

Durante a década de noventa, iniciou-se um processo de revisão da ICIDH, mobilizado pela compreensão da verdadeira natureza da incapacidade, a qual não devia ser concebida como sinônimo de limitação funcional, mas ser analisada por meio de uma perspectiva ambiental/ social (HURST, 2003). Em 2001, foi aprovada pela Assembléia Mundial de SaúdeaInternational Classification of Functioning, Disability and $\mathrm{H}$ ealth - ICFDH (WHO, 2001), traduzida em português como Classificação Internacional de Funcionalidade, Incapacidade e Saúde.

A funcionalidade, na ICFDH, éum termo amplo queenvolve a função e estrutura corporal, atividade e participação, sendo constituída dos aspectos positivos da interação entre um indivíduo eos fatores contextuais. A incapacidade, nesse modelo, resulta da interação entre a disfunção manifestada pelo indivíduo, a limitação de suas atividades e a restrição na participação social, bem como dos fatores ambientais que podem facilitar ou dificultar seu desempenho e participação (OMS, 2002; FARIAS; BUCHALLA, 2005; BALES et al., 2006).

A deficiência física (DF) é definida pelo MEC no documento "Parâmetros Curriculares Nacionais - Adaptações Curriculares (PCNs)" como "uma variedade de condições não-sensoriais que afetam o indivíduo em termos de mobilidade, de coordenação motora geral ou de fala, como decorrência de 
lesões neurológicas, neuromusculares e ortopédicas, ou ainda, de malformações" (BRASIL, 1999, p.26).

Wolf et al. (1990) classificam as deficiências físicas em: a) desordens do Sistema N ervoso Central, que podem ser exemplificadas pel a paral isia cerebral, epilepsia, espina bífida, lesões medulares e outras condições e b) deficiências esqueléticas e musculares. De acordo com essa classificação, as doenças neuromusculares, incluída a Distrofia Muscular Progressiva (DMP), pertencem ao grupo das deficiências musculares.

Florence (2002) define DMP como um grupo de miopatias geneticamente determinadas que apresenta um curso degenerativo constantemente progressivo. Entre as miopatias infantis o tipo mais comum, prevalente, grave e incapacitante é a Distrofia Muscular de Duchenne (DMD).

A DMD é uma doença genética que causa fraqueza muscular progressiva, leva à paralisia total e à morte súbita nos últimos anos da adolescência ou em adultos jovens (HALLUM, 2004). Segundo Webb (2005), a incidência de DMD é de, aproximadamente, um em 3.500 meninos e uma em 50.000 .000 meninas, nascidos vivos e, no caso da mãe ser portadora do gene, o risco é de $50 \%$ para filhos do gênero masculino. De acordo com Reed (2002), as mulheres podem herdar o gene sem manifestações clínicas.

As primeiras manifestações aparecem entre três e cinco anos, quando a criança apresenta dificuldade de sentar-se, ficar em pé, e andar, e cai com freqüência. Por volta dos cinco anos de idade, a criança começa a apresentar dificuldade em subir escadas e pode tornar-se incapaz de correr ou saltar, devido à atrofia muscular evidente, predominantemente nos músculos antigravitacionais e pela substituição do tecido muscular por tecido adiposo e conjuntivo, fenômeno que se manifesta como pseudo-hipertrofia (SHEPHERD, 1996; FLOREN CE, 2002).

Próximo aos oito anos de idade as contraturas dos cordões tendíneos do calcanhar e das faixas ileotibiais levam à marcha sobre artel hos. Entre 12 e 13 anos ocorre perda da deambulação (EDWARDS; FAHAL; THOMPSON, 2000), que evolui para a utilização de cadeiras de rodas. A insuficiência respiratória constitui uma complicação freqüentemente presente nos estágios mais avançados da doença, dado o comprometimento progressivo dos músculos respiratórios. Segundo Narumia e Zanoteli (2005), as deformidades da coluna vertebral agravam a insuficiência respiratória, o que torna o prognóstico de vida destas crianças desfavorável, e leva ao óbito, geralmente no final da segunda década de vida.

Na DMD, os primeiros sintomas são geral mente percebidos na idade pré-escolar por professores ou cuidadores. Além do grau de comprometimento da habilidade de locomoção, esta doença pode causar prejuízo a várias outras funções, tais como habilidades de autocuidados e cognitivas (BILLARD et al., 1998). 
A abordagem fisioterápica deve ser planejada, adotando-se expectativas real istas para as crianças com DMD efamílias, com base nos objetivos fundamentais que consistem em: a) evitar contraturas que possam levar à incapacidade e dor; b) manter a força muscular/ evitar a atrofia por desuso; c) favorecer habilidades funcionais; e d) manter a função respiratória (HALLUM, 2004), por meio de fisioterapia motora, respiratória e aquática (NARUMIA; ZANOTELI, 2005).

Segundo Hallum (2004), no ambiente de tratamento de saúde atual deindivíduos em estagio avançado de comprometimento, os fisioterapeutas atuam principalmente como consultores, mais do que provedores de serviço diretos. Muitos dos programas de exercício para as crianças devem ser realizados em casa, pelos cuidadores.

Webb (2005) relata que os pais das crianças com DMD acreditam ser importante intervir junto à escola para proporcionar apoio, ajuda e segurança para o sucesso acadêmico e participação social no ambiente educacional. Em relação às abordagens de tratamento das deficiências, a ICFDH (OMS, 2002) distingue intervenção com vistas a melhorar limitações individuais e/ ou funcionalidade social pela modificação de funções intrínsecas/ estruturas corporais, com intervenções primariamente médicas ou reabilitadoras. Essa classificação aborda, ainda, a existência de outras estratégias de intervenções reabilitadoras, focadas no contexto real de desempenho do indivíduo, orientadas tanto para melhorar sua capaci dade, quanto para modificar o ambiente por meio da eliminação de barreiras e/ ou criação de facilitadores ambientais, no sentido de expandir o desempenho de ações e tarefas da vida diária. A Declaração de Salamanca (1997) preconiza que as escolas regulares devam se adequar e estruturar para atender à diversidade, por meio de uma pedagogia centrada na criança, capaz de responder às suas necessidades. De acordo com Omote (2004), a educação básica brasileira tem sido objeto de intensas discussões e reformas em busca de adequação da escola às novas demandas.

Para Bastos e Dutra (2005), a atuação do fisioterapeuta na escola consiste em: proporcionar posicionamento adequado ao aluno; verificar a sua disposição e adequar seu mobiliário em sal a de aula e prescrever ou confeccionar adaptações para favorecer sua função e melhorar seu rendimento escolar.

Para os indivíduos com deficiência, a tecnol ogia assistiva constitui-se um item, peça ou produto que, ao ser utilizado, mantém ou aumenta suas habilidades funcionais; contribui para a melhora da capacidade de aprender, competir, trabalhar e interagir com a família e amigos (GALVÃ O; OZU, 2005). Aspectos, estes, essenciais na determinação da qualidade de vida.

Segundo Harding (2001), qualidade de vida pode referir-se a aspectos do bem-estar físico, psicossocial e social, bem como ambientais e do padrão de vida da pessoa. Para N arumia e Zanoteli (2005), o fisioterapeuta e toda a equipe 
de reabilitação têm papel fundamental na promoção de melhor qualidade de vida do paciente e sua família.

Ketelaar et al. (2001) afirmam que um programa de terapia funcional traduz uma forma sistemática de tentar solucionar problemas funcionais das crianças. Esses autores destacam que a principal característica dessa abordagem é a participação dos pais em todos os estágios do programa no intuito de atingir os objetivos, indicando os principais problemas relacionados ao desempenho diário da criança, com foco na sua resolução, em situações reais.

Segundo levantamento realizado pela Secretaria de Educação de um município do interior do Estado do Paraná, no ano de 2006 havia cerca de 105 alunos com DF matriculados no primeiro ciclo do ensino fundamental em escolas municipais, cinco dos quais com DMD, havendo dois destes feito parte desse estudo (ALPINO et al., 2006).

Este estudo teve por objetivo verificar os efeitos de uma proposta de consultoria colaborativa da fisioterapia junto às professoras de dois alunos com DMD, inseridos em classe comum de uma mesma escola da rede municipal de ensino, com vistas a promover apoio especializado a esses alunos, às suas professoras e aos pais de um deles, a fim de melhorar sua participação e conforto em contextos significativos para o seu dia-a-dia.

\section{MÉTOdo}

Este estudo foi aprovado pelo Comitê de Ética em Pesquisa do HUL/ UEL, conforme o parecer número 075/ 06. Foi obtido o consentimento livre e esclarecido dos pais dos participantes mediante explanação dos objetivos, procedimentos, riscos e benefícios do mesmo, de acordo com a Resolução 196/ 96, do Conselho Nacional de Saúde.

O estudo envolveu dois participantes do gênero masculino, com diagnóstico clínico de DMD e suas professoras de sala e de Educação Física. Um aluno (A 1) com idade de nove anos e o outro (A 2) com 10 anos, que freqüentavam

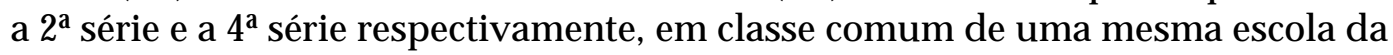
rede municipal de ensino de uma cidade do interior do Paraná, integrantes do projeto de extensão universitária da UEL: Programa de Promoção e A poio à Inclusão de Crianças com Deficiência Física (PROPAI-DF).

O A 1 tinha dificuldade de aprendizagem, segundo informações da professora de sala. A presentava sobrepeso, com alterações posturais e mioarticulares como: ombros protraídos, acentuação da lordose lombar, hiperextensão de joelhos, pseudo-hipertrofia de panturrilhas e pés com tendência a inversão. Além disso, A 1 evidenciava princípio de deficit funcional, expresso pela dificuldade em se el evar do solo (levantar miopático), marcha bamboleante (anserina), dificuldade em correr e subir escadas. A criança era independente em relação à higiene, vestuário, alimentação, locomoção e atividades escolares. 
O A 2 não evidenciava deficit cognitivo, porém apresentava grave comprometimento da função motora, caracterizado por extrema fraqueza muscular e pela falta de controle antigravitacionário da cabeça, tronco emembros. O A 2 era obeso, apresentava movimentação ativa apenas em punhos e mãos, perdeu a capacidade de deambular aos sete anos de idade e utilizava cadeira de rodas impulsionada por outra pessoa. Era totalmente dependente na higiene, vestuário, locomoção e mudanças de decúbito, e semidependente na al imentação, desde que os utensílios estivessem ao seu alcance, apoiados numa superfície, e ele utilizasse canudo para ingestão de líquidos. Conseguia pintar e escrever/ copiar apenas textos curtos devido à fadiga. Evidenciava desvio lateral significativo da coluna vertebral (escoliose), deformidade em flexão de cotovelos e joel hos, e pés eqüinos decorrente de contratura muscular.

O levantamento das barreiras arquitetônicas, a avaliação do mobiliário escolar ea investigação das necessidades de apoio dos alunos partici pantes foram feitos mediante preenchimento de um instrumento denominado Instrumento para Caracterização dos Alunos com Deficiência Física e das Condições de A cessibilidade e Mobilidade na Escola Regular (A LPINO, 2003). Foram empregados, ainda, quatro roteiros semi-estruturados, elaborados pelas pesquisadoras para entrevistar os alunos participantes, suas professoras de sala, suas professoras de Educação Física e mãe de A 2, com o intuito de obter dados quenorteassem a intervenção. A s respostas foram registradas pel as pesquisadoras por meio de anotação e as informações foram confirmadas/ complementadas pelos participantes ao término da entrevista.

As entrevistas com os alunos acometidos por DMD buscaram investigar: sua participação nas atividades de sala e Educação Física; suas necessidades para realizar as atividades propostas; seus interesses; suas expectativas em relação às professoras e colegas; e o grau de satisfação quanto aos aspectos citados. As entrevistas com as professoras de sala (PS1 e PS2) e de Educação Física (EF1 e EF2) tiveram a finalidade de investigar: o conhecimento sobre a condição dos alunos participantes e os riscos ao seu bem-estar; as dificuldades em lidar com os riscos; a necessi dade de adaptações dos materiais, atividades didáticas, eatividades físicas/ brincadei ras para inclusão desses al unos nas aulas de Educação Física.

Final mente, a mãe de A 2 também foi entrevistada, a fim de investigar a existência de dificuldades em lidar com o filho no dia-a-dia; suas expectativas quanto à atuação da fisioterapia e interesse em orientações específicas.

As visitas à escola dos alunos participantes tiveram por objetivos: conhecer os aspectos físicos e funcionais do A 1 e do A 2; observar sua interação com os colegas, professoras de sala e de Educação Física; e obter informações a respeito das expectativas dessas professoras quanto à sua participação nas atividades escolares. As pesquisadoras acompanharam os alunos participantes durante cinco períodos letivos, uma vez por semana, dentro da sala de aula, no 
intervalo e na aula de Educação Física. Durante as visitas foi possível observar as atividades propostas pelas professoras e as dificuldades dos alunos participantes em realizá-las, bem como seu posicionamento e os materiais utilizados. As observações foram registradas seguindo-se o modelo de diário de campo para análise posterior.

O fato da mãe do A 2 relatar dificuldades em lidar com o filho em casa, determinou que fossem feitas visitas à sua residência a fim de se conhecerem as condições de participação/ convivência deste aluno no ambiente familiar, de modo a obterem-se dados que melhor subsidiassem a Intervenção. As visitas residenciais possibilitaram observar: a forma como os pais realizavam as transferências posturais do A2 para o sofá, cadeira de banho, cama, cadeira de rodas e carro; qual o local e quais os posicionamentos nos quais o aluno passava maior parte do tempo; o modo como fazia as refeições e tarefas escolares; e se havia a fal ta de adaptação da mobília ou outros recursos de tecnologia assistiva. Foram discutidas algumas possibilidades de torná-lo mais participativo no ambiente natural, considerando-se as dificuldades e ansei os dos pais e da criança.

As orientações às professoras de sala e de Educação Física do A 1 e do $A 2$ sobrea doença, cuidados, posicionamento adequado, adaptação da mobília edas atividades foram proporcionadas por meio de palestras interativas ${ }^{4}$. Houve, ainda, treinamento quanto à realização de transferências posturais e de posi cionamento adequado das crianças com DF na cadeira de rodas e na cadeira comum, respctivamente. A compreensão dos conteúdos trabalhados durante as palestras foi verificada por meio de um questionário sobre DMD que avaliava o conhecimento científico, mitos e concepções das professoras participantes sobre tal condição, assim como a educação dos alunos por ela acometidos.

\section{Resultados}

Inicialmente, as professoras participantes revelaram inexperiência, apreensão einsegurança no atendimento dos al unos com DMD. A pós as pal estras sobre DF ministradas pela equipe do PROPAI-DF e as orientações promovidas pelas fisioterapeutas na escola, as professoras relataram ter adquirido maior conhecimento sobre a condição desses alunos.

As visitas à escola dos alunos participantes permitiram conhecer: as necessidades de apoio físico para as atividades educacionais e de assistência nas habilidades de autocuidados, transferências e locomoção/ transporte; as necessidades de adaptações e/ ou modificações ambientais; e as medidas dos alunos participantes para desenvolvêlas. O Quadro 1 apresenta as condições de

\footnotetext{
${ }^{4}$ II Ciclo de Palestras da Rede Municipal de Ensino de Londrina sobre Deficiência Física e suas Implicações Educacionais, ministrado pela equipe do Projeto de Extensão Universitária denominado Programa de Promoção e A poio à Inclusão de Crianças com Deficiência Física (PROPAI-DF), no ano de 2006.
} 
independência funcional e de necessidade de auxílio físico do A 1 e do A 2 na escola.

\begin{tabular}{|c|c|c|c|}
\hline \multicolumn{2}{|c|}{ Atividades acadêmicas } & Movimento/atividade física & Autocuidados \\
\hline \multirow[b]{2}{*}{$\begin{array}{l}\text { Realiza } \\
\text { com } \\
\text { dificuldade } \\
\text { ou auxílio }\end{array}$} & $\begin{array}{l}\quad \text { A1 } \\
\text {-Copia da atividade; } \\
\text {-Conta; } \\
\text {-Encontra as } \\
\text { páginas do livro. } \\
\end{array}$ & $\begin{array}{l}\text { A1 } \\
\text {-Anda pelo pátio evitando quedas, } \\
\text { quando em fila; } \\
\text { - Acompanhar os colegas nas } \\
\text { atividades de educação física. }\end{array}$ & $\begin{array}{c}\text { A1 } \\
\text {-Não necessita de auxílio. }\end{array}$ \\
\hline & \begin{tabular}{l}
\multicolumn{1}{c}{$\mathrm{A} 2 \mathrm{~d}$} \\
-Não necessita de \\
auxílio.
\end{tabular} & - Joga xadrez. & \begin{tabular}{l}
\multicolumn{1}{c}{ A2 } \\
- Utiliza “papagaio", com \\
assistência; \\
- Bebe água com canudo e o copo \\
apoiado; \\
- Alimenta-se com membros \\
superiores apoiados em mesa alta \\
e aproximando a cabeça da colher; \\
- Escovar dentes com escova \\
elétrica e assistência física.
\end{tabular} \\
\hline \multirow[b]{2}{*}{ Incapaz de } & $\begin{array}{c}\text { A1 } \\
\text { - Ler texto do livro. } \\
\end{array}$ & $\begin{array}{c}\text { A1 } \\
\text { - Subir em mobília alta. }\end{array}$ & $\begin{array}{c}\text { A1 } \\
- \\
\end{array}$ \\
\hline & $\begin{array}{c}\mathrm{A} 2 \\
-\end{array}$ & \begin{tabular}{l}
\multicolumn{1}{c}{ A2 } \\
- Andar, subir/descer; \\
- Transferências; \\
- Atividades de educação física \\
(correr, jogar bola, pular corda); \\
- Pegar materiais de dentro da \\
mochila e os que caem no chão; \\
- Tocar a cadeira de rodas.
\end{tabular} & \begin{tabular}{l}
\multicolumn{1}{c}{ A2 } \\
- Usar o vaso sanitário na escola; \\
- Adequar à postura na cadeira e \\
carteira; \\
- Posicionar os membros \\
superiores na cadeira de rodas; \\
-Tomar banho.
\end{tabular} \\
\hline
\end{tabular}

Quadro 1 - Condições de independência funcional ou necessidade de auxílio físico do A 1 e do A2 em relação a atividades acadêmicas, atividades físicas e de autocuidados.

As adaptações desenvolvidas para o A 1 consistiram em: adequação das dimensões da mobília escolar aos seus parâmetros antropométricos, sem que sua carteira ficasse desproporcional em relação às dos colegas de sala. Foi adaptado um suporte confeccionado em madeira para os pés do aluno, visto que esses não se apoiavam no chão. Desse modo, evitou-se que permanecessem suspensos, retardando-se a instalação de deformidade dos pés em plantiflexão. A o final, foi possível observar que a adequação das medidas da mobília e o apoio dos pés forneceram maior estabilidade ao aluno, que permaneceu sentado sobre os ísquios e melhorou sua postura. 
Para o A 2, foi adaptada uma mesa feita de madeira, com recorte na altura do tórax (com a finalidade de apoiar o tronco) e medidas mais amplas que a carteira comum, própria para o uso de cadeira de rodas.

A visita domiciliar permitiu identificar aspectos inadequados em relação ao mobiliário, assim como a necessidade de algumas adaptações que poderiam favorecer a participação/ desempenho do A2 nas habilidades de autocuidados, tarefas escolares e atividades lúdicas.

$\mathrm{Na}$ residência do $A 2$, optou-se pelo desenvolvimento de algumas adaptações e recursos de tecnologia assistiva a fim de proporcionar ao aluno uma posição opcional para o repouso e melhorar seu posicionamento durante as refeições, higiene bucal, tarefas escolares e atividades de lazer. Para tanto, foi adaptada uma rampa de madeira, forrada com espuma, de altura e largura equivalentes à da cadeira de rodas. Foi confeccionada, também, uma mesa de madeira, cujo modelo e dimensões eram similares às da escola. Para promover alguma autonomia na habilidade de higiene bucal foi fornecida uma escova de dente elétrica e orientada sua utilização, com o apoio dos membros superiores sobre a mesa adaptada.

Foram confeccionados, ainda, dois acessórios para favorecer as transferências posturais do A 2 em casa, posto que seus pais referiram dificul dades para realizá-las, devido ao peso excessivo do corpo e fraqueza dos músculos. Um dos acessórios assemel hava-se a uma rede, feito de tecido resistente (fio denylon), com al ças laterais; o outro, um cinto confeccionado de tecido (brim), fechado com velcro. Os pais foram orientados a sustentar o A 2 por meio desses acessórios, durante as atividades de transferências/ mudanças de decúbito.

As entrevistas possibilitaram conhecer tanto a avaliação dos alunos participantes e da mãe do A 2 sobre a intervenção realizada, quanto suas expectativas.

O A 1 relatou sentir-se satisfeito e mais confortável na escola, graças às modificações/ ações desenvolvidas: mudança de lugar na sala de aula; adaptação do mobiliário e orientações quanto ao uso deste.

Em relação à adaptação da mesa/ carteira na escola, o A 2 revelou satisfação, maior conforto e melhora da condição para a escrita. Foi possível observar adequação da postura dos ombros, outrora el evados etensos. A utilização dos lápis JUMBO (Faber- Castell) contribuiu para a escrita, uma vez que o aluno referiu maior facilidade em apreender tais lápis, necessitando despender menor quantidade de força para o traçado.

Sobre as expectativas dos alunos participantes quanto à atitude de seus colegas e professoras, o A 1 e o A 2 relataram insatisfação quanto ao relacionamento com alguns colegas de classe, e desejo de serem auxiliados por suas professoras de sala e de Educação Física, quando necessitassem. A firmaram, 
ainda, que não mudariam nada na escola, mesmo existindo limitações eobstáculos ambientais que pudessem dificultar seu acesso e participação.

Os acessórios confeccionados (rede e cinto) não foram eficazes para favorecer as transferências posturais, visto que os pais relataram dificuldade em usá-los e o A 2 demonstrou insegurança na sua utilização, mesmo depois do treinamento realizado pelas pesquisadoras. Para os pais, o A 2 demonstrou maior interesse em realizar atividades em casa, principalmente após adaptação da mesa, que proporcionou ao aluno local adequado para fazer refeições, atividades escolares elúdicas, como: pintar; desenhar; ler; fazer tarefa; brincar com carrinhos; jogar videogame e jogos de tabuleiro. Proporcionou, também, algum grau de independência na higiene bucal com utilização da escova de dente elétrica. $O$ fato do A 2 conseguir realizar este cuidado contribuiu para sua satisfação.

Devido ao excesso de peso do A2, a maior dificuldade relatada por seus pais consistia na realização das transferências posturais do filho para: o sofá; a cadeira de rodas; o carro e mudanças de decúbito no leito, durante a noite. Finalmente, foi possível verificar que, entre as adaptações desenvolvidas, a rampa, a escova de dente elétrica e a mesa foram consideradas, pelo A 2 e seus pais, de maior utilidade. Enquanto os acessórios para transferência foram julgados recursos ineficazes, uma vez que demandavam dois adultos para seu manuseio/ utilização e geravam insegurança à da criança.

Inicialmente, a mãe relatou que não tinha expectativas quanto à atuação da Fisioterapia e que todas as orientações seriam bem-vindas. A pós a Intervenção, revelou sentir-se satisfeita com a abordagem fisi oterápica orientada ao bem-estar de sua família, conforme expressam os relatos a seguir:

- "Fiquei feliz, foi muito bom vocês terem se preocupado com o meu filho, comigo e meu marido. Foi muito bom!" (Mãe de A2).

- "N unca ninguém fez o que vocês fizeram por ele... mesmo ele conhecendo um monte de fisioterapeutas, nunca nenhum pensou em vir aqui em casa para ver como é a vida do meu filho" (Mãe de A2).

\section{DiscusSÃo}

Educadores do ensino regular e da educação especial têm participado, historicamente, de um sistema que divide os professores do mesmo modo que isola e categoriza os alunos (SA PON-SHEVIN, 1988 apud WOOD, 1998). A intensa necessidade de assessoria externa e capacitação dos professores do ensino regular para o atendimento educacional de alunos com deficiência refleteseu despreparo, certamente justificado pelo tempo transcorrido em que a educação desses alunos esteve inteiramente sob a responsabilidade do saber especializado (ALPINO, 2008). 
O fato das professoras participantes deste estudo revelarem inexperiência, apreensão e insegurança no atendimento do aluno com DMD reforça a necessi dade de investir na capacitação específica dos educadores a fim de que eles desenvolvam competências relacionadas não só a diferentes formas de proporcionar instrução, usar equipamento de tecnologia assistiva, adaptar conteúdos, atividades e materiais, mas também à aptidão para planejar o ensino earranjar em ambiente de aprendizagem favorável à acessi bilidade e participação de todos os alunos (LAUAND, 2000; ALPINO, 2003).

Segundo Omote (2004), as discussões sobre as necessidades dos indivíduos com deficiência, inicialmente confinadas a um círculo restrito composto por familiares, profissionais da educação especial e da reabilitação, têm-se estendido para o cenário da educação geral. Muitos educadores estão buscando qualificação para atender às novas demandas, igualmente um número crescente de pais tem-se mobilizado em busca do direito de seus filhos com deficiência. A participação das professoras do A 1 e do A 2 nas palestras ministradas pela equipe do PROPAI-DF e seu interesse por este estudo sugere que estejam em busca de capacitação específica para mel hor atender seus alunos com DMD.

De acordo com Florence (2002), a DMD apresenta um curso degenerativo constantemente progressivo, grave e incapacitante, com perda da deambulação entre nove e 10 anos. No entanto, entre os al unos participantes foi possível observar diferentes cursos de progressão da doença, traduzidos na evolução mais acelerada do quadro degenerativo muscular do A2, que perdeu a marcha aos sete anos, passando a utilizar cadeira de rodas desde então; e na deterioração mais lenta, manifestada pelo A 1, que aos nove anos ainda apresentava marcha sem apoio, embora os dois fizessem tratamento fisioterápico (motor, respiratório e aquático).

Não obstante o deficit motor grave do A 2, sua professora relatou não ter percebido nenhuma dificuldade cognitiva. Em contrapartida, a professora do A 1 indicou que este aluno apresentava dificuldade de aprendizagem, não acompanhava os colegas nas atividades propostas e parecia ter discreto deficit cognitivo. Sobre este aspecto, Billard et al. (1998) relataram que em seu estudo al gumas crianças com DMD apresentaram rebaixamento do QI equea deficiência intelectual parecenão ser progressiva, conformeo curso da deterioração muscular.

A identificação das necessidades dos alunos participantes in loco determinou as adaptações do mobiliário e dos materiais que contribuíram para o conforto e participação do A 1 e do A2, na escola. Entretanto, devido ao grave comprometimento funcional do A2, as ações consideradas mais efetivas/ significativas compreenderam as adaptações e orientações desenvolvidas no ambiente domiciliar. Segundo Edwards (2003), para melhorar a qualidade de vida de indivíduos com deficiência é importante conhecer e reduzir as barreiras 
sociais e ambientais existentes, além de promover sua inclusão nas atividades escolares, familiares e na comunidade.

Ao entrevistar alunos com paralisia cerebral inseridos no ensino regular, Alpino (2003) constatou que maior parte dessas crianças não tinha expectativas em relação aos colegas de classe, porém, esperavam mais compreensão dos professores. A maioria relatou, ainda, que não mudaria nada na escola, com quanto identificassem fal has na estrutura física. De modo similar, o A 1 e o A 2 revelaram o desejo de serem auxiliados por suas professoras e complementaram dizendo que não mudariam nada no ambiente escolar. Essa fala pode traduzir a falta de conhecimento desses alunos sobre a existência de facilitadores ambientais capazes de proporcionar-Ihes maior conforto eautonomia, visto que não dispunham de tais recursos nem mesmo em suas resi dências. Pode refletir, ainda, a consciência da dificuldade de conseguirem outra oportunidade escolar viável à sua realidade.

A adoção de postura mais adequada e o relato de satisfação e maior conforto dos alunos participantes na escola, após adaptação do mobiliário, confirmam a importância das modificações no ambiente escolar com vistas a promover o bem-estar e a facilidade do movimento de alunos com deficiência motora. Segundo Dutra e Bastos (2005), proporcionar posicionamento adequado ao aluno, por meio da adaptação e disposição do mobiliário na sala de aula, e o prescrever/ confeccionar adaptações para melhorar sua função constituem objetivos da atuação da fisioterapia na escola, podendo aumentar o rendimento escolar. Essas autoras sugerem, ainda, que a utilização de uma cadeira/ mesa adequada pode facilitar uma série de atividades, por exemplo, a diminuição do trabal ho muscular eda sobrecarga nos membros inferiores ea redução do consumo energético.

A princípio, a proposta deste estudo era restringir a investigação ao ambiente escolar, junto às professoras e aos alunos participantes. No decorrer do trabalho identificou-se a necessidade de estender a investigação ao ambiente domiciliar do A2, devido ao fato deste aluno apresentar total dependência dos cuidados dos pais e estes manifestarem grande interesse por orientações especializadas da fisioterapia.

De acordo com Shepherd (1996), muitos problemas de ordem prática podem ser solucionados ou previstos pelo profissional fisioterapeuta e/ ou terapeuta ocupacional por meio de visitas domiciliares periódicas e orientações aos pais. Além disso, podem ser discutidas atividades delazer/ lúdicas praticadas pela família e que sejam mais apropriadas à participação da criança, evitando-se que permaneça longo tempo numa mesma posição. As adaptações (mesa, escova de dente el étrica e rampa) desenvolvidas na residência do A 2 permitiram algum grau de autonomia/ independência no desempenho das seguintes habilidades: alimentação; higiene bucal; tarefas escolares e atividades lúdicas, além de proporcionar-Ihe uma posição alternativa para descanso. O desenvolvimento e/ 
ou mel hora dehabilidades funcionais devem ser proporcionados pela fisioterapia, uma vez que o principal objetivo fisioterápico junto ao indivíduo com disfunção motora é promover maior independência e melhor qualidade de vida.

A intervenção realizada no ambiente domiciliar proporcionou maior interação entre o fisioterapeuta e os pais do A 2, possibilitando a troca de informações valiosas e a promoção de orientações especializadas. A melhora do conforto e participação do A 2 em al gumas atividades de autocuidado e ao brincar resultou em satisfação do aluno ede seus pais, apontando benefícios para a família. Para Narumia e Zanoteli (2005), o fisioterapeuta, assim como toda a equipe de reabilitação, tem papel fundamental na tentativa de estabel ecer mel hor qual idade de vida, mediante o trabal ho com o paciente e a família.

Ketelaar et al. (2001) afirmaram que um programa de terapia funcional traduz uma forma sistemática detentar solucionar problemas funcionais das crianças, cuja principal característica é a participação dos pais em todos os estágios, indicando os principais problemas relacionados ao desempenho diário da criança e buscando sua resolução em situações reais. Para Ratliffe (2002), a intervenção fisioterápica com foco no contexto real de desempenho do indivíduo traduz uma abordagem ecológica, amplamente fundamentada na funcional idade da pessoa com DF e deve considerar: suas necessidades; as atividades prementes, específicas aos diferentes ambientes; e as habilidades que o indivíduo precisará ter para adaptar-se a esses ambientes.

\section{CONCLUSÃo}

Este estudo permitiu o conhecimento das dificuldades e necessidades de duas crianças portadoras de DMD, na escola e em casa e possibilitou conhecer suas expectativas em relação à escola, aos colegas e às professoras de sala e Educação Física. A lém disso, essas crianças demonstraram vivenciar um contexto de aprendizagem significativa e motivante em classe comum.

A atuação do fisioterapeuta como colaborador junto à escola regular poderá contribuir para a capacitação específica dos professores e para a promoção da participação e do bem-estar de al unos com DMD. N esta proposta, as ações do fisioterapeuta podem abranger tanto palestras/ orientações especializadas, quanto adaptações ambientais do mobiliário, de equipamentos de tecnologia assistiva e de materiais que favoreçam o posicionamento adequado, a mobilidade, a real ização de atividades escolares e de autocuidados, ainda que de limitados. Esta abordagem fisioterápica deve fundamentar-se no conhecimento real das necessidades dos alunos e das dificuldades dos educadores, estando sua viabilidade vinculada à convivência do profissional no ambiente escolar, o que Ihe permiteobservar a rotina, ouvir o professor eo al uno eidentificar os problemas em ambienteespecífico esignificativo para buscar soluções mais efetivas, conforme proposto pela abordagem ecológica/ funcional. 
As adaptações residenciais e as orientações aos pais constituíram-se aspectos fundamentais da abordagem fisioterápica com vistas a melhorar a qualidade de vida do aluno gravemente comprometido e de sua família, porquanto possibilitaram maior segurança aos pais e conforto à criança.

O tratamento fisioterápico da criança com DMD e seu atendimento educacional são pouco abordados na literatura, sobretudo quando o enfoque é sua inclusão na escola comum. O modelo de consultoria colaborativa prestada pelo fisioterapeuta propõe extrapolar os limites do tratamento ambulatorial, estendendo o conhecimento especializado ao ambiente escolar. E aponta para a necessidade de novos estudos que subsidiem as práticas dos educadores e enfoquem a abordagem fisioterápica de uma perspectiva fundamentalmente funcional e ecológica, junto aos portadores de deficiência, suas famílias e escola.

\section{REFERÊNCIAS}

ALPINO, A.M.S. 0 aluno com Paralisia Cerebral no ensino regular: ator ou expectador do processo educacional? 2003. 141f. Dissertação (M estrado em Educação Especial) Universidade Federal de São Carlos, São Carlos, 2003.

ALPINO, A.M.S. Consultoria Colaborativa Escolar do Fisioterapeuta: acessibilidade e participação do aluno com paralisia cerebral em questão. 2008. 191f. Tese (Doutorado em Educação Especial) - Universidade Federal de São Carlos, São Carlos, 2008.

ALPINO, A.M.S. et al. PROPAI-DF - Programa de Promoção e A poio a Inclusão de Crianças com Deficiência Física:um projeto de extensão universitária. Estac@o: Revista Eletrônica, Londrina, v.4, n.6, dez.2006. Disponível em: http:/ / www.proex.uel.br/ $\begin{array}{llllllll}\mathrm{e} & \mathrm{s} & \mathrm{t} & \mathrm{a} & \mathrm{c} & \mathrm{a} & 0\end{array}$ indexphp?arq=ARQ_at\&FWS_Ano_Edicao-A\&FWS_N_Edicao=-6FWS_N_Texto=106FWS_Cod_Categoria=1

BALES, M.E. et al. Qualitative assessment of the international classification of functioning, disability, and heal th with respect to the desiderata for controlled medical vocabularies. International Journal of M edical Informatics, Shannon, v. 75, n. 5, p. 384 395, May 2006.

BASTOS, V.A.; DUTRA, F.C.M. A tuação da fisioterapia na escola visando o deficiente físico. In: MOURA, E.W.; SI LVA, P.A.C. (Org.). A spectos Clínicos e Práticos da R eabilitação. São Paulo: Artes Médicas, 2005. p. 657-667.

BILLARD, C. et al: Cognitivefunctions in D uchennemuscular dystrophy and spinal muscular atrophy. Neuromuscular Disord 2: 371-378, 1998.

BRASIL, Ministério da Educação, Secretaria de Educação Fundamental, Secretaria deEducação Especial. Parâmetros Curriculares N acionais: adaptações cur riculares, estratégia para a educação de alunos com necessidades educacionais especiais. Brasília, 1999. 
BRA SIL. Ministério da Justiça. Secretaria Nacional dos Direitos Humanos. D eclaração de Salamanca e linhas de ação: sobre necessidades educativas especiais. 2. ed. Brasília: Corde, 1997.

EDWARDS, R.H.T.; FAHAL, I.; THOMPSON, N. Distúrbios musculares In: STOKES, M. Cash. N eurologia para fisioterapeutas. São Paulo: Premier, 2000. p. 215-221.

FARIAS, N.; BUCHALLA, C. M. A Classificação internacional de funcionalidade, incapacidade e saúde da Organização Mundial de Saúde: conceitos, usos e perspectivas. Revista Brasileira de Epidemiologia, São Paulo, v. 8, n. 2, p. 187-193, jun. 2005.

FLORENCE, J.M. Doenças neuromusculares na infância eintervenção fisioterapêutica. In: TECKLIN, J.S. (Org.). Fisioterapia Pediátrica. 3. ed. São Paulo: Artmed, 2002. p. 188-205.

GALVÃO, M.C.S.; OZU, M.A.U. Fisioterapia na paralisia cerebral In: MOURA, E.W.; SILVA, P.A.C. (Org.). A spectos Clínicos e Práticos da Reabilitação. São Paulo: Artes Médicas, 2005. p. 27-46.

HALLUM, A. Doenças Neuromusculares. In: UMPHRED, D.A. (Org.). Reabilitação N eurológica. 2. ed. São Paulo: Manole, 2004. p. 384-436.

HARDING, L. Children's quality of life assessments: a review of generic and health related quality of life measures completed by children and adolescents. Clinical Psychology and Psychotherapy, 8, 76-96, 2001.

HURST, R. The international disability rights movement and the ICF. Disability and Rehabilitation, London, v.25, n.11/ 12, p. 572-576, Jun. 2003.

KETELAAR et al, Effects of a Functional Therapy Program on Motor Abilities of Children with Cerebral Palsy, P hysical Therapy, v. 81, n.9, September, 2001.

LAUAND, G. B. A. A cessibilidade e formação continuada na inserção escolar de crianças com deficiências físicas e múltiplas. 2000. 121 f. Dissertação (M estrado em Educação Especial) - Universidade Federal de São Carlos, São Carlos, 2000.

NARUMIA, L.C.; ZANOTELI, E. Aspectos clínicos e abordagem fisioterapêutica. In: MOURA, E.W.; SILVA, P.A.C. (Org.). A spectos Clínicos e Práticos da Reabilitação. São Paulo: Artes Médicas, 2005. p. 221-245.

OMOTE, S. Inclusão: intenção e realidade. Marília: Fundepe, 2004.

REED, U.C. Doenças neuromusculares. Jornal de Pediatria, Rio de Janeiro, v. 78, Supl. $1,2002$.

SHEPHERD, R.B. Fisioterapia em Pediatria. 3. ed. São Paulo: Santos, 1996.

WEBB, C.L. Parents' perspectives on coping with Duchenne Muscular Dystrophy. Blackwell Publishing Ltd, 2005. 
PENA, F. F.; ROSOLÉM ,F.C.; ALPIN O, Â.M.S.

[WHO] World Health Organization. International Classification of Impairments, D isabilities and H andicaps. Geneva: WHO; 1980.

[WHO] World Health Organization. International Classification of F unctioning, D isability and $\mathrm{H}$ ealth: ICF. World Health Organization; 2001.

WOLF, B. et al. Instructor's edition for human exceptionality. 3. ed. Boston: Allyn and Bacon, 1990.

WOOD, M. Whose job is it anyway? educational roles in inclusion. Exceptional Children, Washington, v. 64, n. 2, p. 181-195, 1998.

Recebido em 02/ 06/ 2008

Reformulado em 18/ 11/ 2008

A provado em 04/ 12/ 2008 